\title{
Impact of Music on Behavior during Dental Treatment
}

\author{
Jennifer Brookins ${ }^{1}$, Keith T Williams ${ }^{2}$ and Tabitha Brookins²* \\ ${ }^{1}$ Principal Investigator, Alabama State University, USA \\ ${ }^{2}$ Study Co-investigator, Alabama State University, USA \\ *Corresponding author: Tabitha Brookins, PhD, Study Co-investigator, Alabama State University, 915 S. Jackson Street, Montgomery, AL 36105
}

Submission: 眥 October 02, 2017; Published: 眥 February 12, 2018

\begin{abstract}
Purpose: The primary objective of this clinical research is to investigate the impact of music therapy on the behavior of children undergoing operative dental treatment. This project aims to propose therapeutic techniques which apply music to aid in pain and anxiety control and/or reduction during dental treatment.
\end{abstract}

Methods: A retrospective chart review looking at the intervention of music therapy during dental treatment at Bronx-Lebanon Hospital Center wil be conducted. The target subjects will be children between ages of 6 and 12 years old who meet inclusion and exclusion criteria. A chart review will be conducted evaluating Frankl score of children with and without music during dental treatment. Music will be provided as a standard of care during dental treatment.

Results: Interpretation of Paired T-Test Results: With a positive difference of 0.8039 in the Frankl score and a corresponding p-value of $<0.0001$, it implies that patients who received music therapy had significantly higher Frankl Score compared to those who did not receive music therapy.

Conclusion: Patient with music therapy had an higher Frankl score compared to children that received dental treatment without music. There was no difference associated with age and Frankl score.

\section{Introduction and Background}

During the past century, the American healthcare system has made tremendous advances in dental procedures. However, there has been limited work addressing patient needs during dental treatment. According to the Ethiopian medical journal, $74.1 \%$ of children face dental anxiety [1]. As a result of these findings, an increasing number of doctors have incorporated non-traditional, less mainstream methods of all eviating pain and anxiety into their daily practice [2].

Dental anxiety is an abnormal fear of visiting the dentist for preventive care or dental procedures [2]. As a result, many patients and parents avoid dental treatment due to anxiety which results in a high prevalence of deterioration of oral health [3]. Patients with extreme anxiety often experience more sensitivity to pain which result in misdiagnosis and inappropriate treatment [4,5]. Previous research has shown that music can be effective in reducing pain and anxiety for children receiving medical treatment [5,6]. According to the research by Kettwich and Brandt in 2007, patients needing IV's placed for chemotherapy did better with music distraction than patients without music distraction [7]. For those patients who received music therapy, there were minimal interruptions during treatment and patients were more compliant [7].

Managing the behavior and anxiety of a child to have a cooperative patient is critical to the success of dental treatment.
It allows providers to render treatment safely, creates a positive experience for patients and improves attitudes towards future visits. This is the reason new, non-aversive techniques which are more effective and acceptable to parents, are being utilized. Due to the documented success in medical setting sand in adult dental patients, many dentists believe that music therapy may be successful in management of pediatric patient $[3,6,7]$.

The primary objective of this research was to investigate the impact of music therapy on the behavior of children under going operative dental treatment. The project aims to propose music for control and reduction of pain and anxiety during dental treatment.

\section{The Frankl Score}

Is a scale use to define behavior [8]. Frankl behavior scale, is a four point selection ranging from definitely positive to definitely negative.

\section{Frankl 1: Definitely negative}

Refusal of treatment; crying forcefully, fearful, or any evidence of extreme negativism

\section{Frankl 2: Negative}

Reluctance to accept treatment; uncooperative; some evidence of negative attitude but not pronounced i.e. sudden withdrawal 


\section{Frankl 3: Positive}

Acceptance of treatment; willingness to comply with the dentist, at times with reservation, but patient follows the dentist's directions cooperatively

\section{Frankl 4: Definitely Positive}

Good rapport with dentist; interested in the dental procedures: laughing and enjoying the situation

\section{Hypothesis}

Patients who received music therapy will have a higher frankl score compared to those who do not receive music therapy.

\section{Methods}

The study was a retrospective study conducted at the BronxLebanon Hospital Center dental clinic. Subjects of the study were consist of children between the ages of 6 and 12that need multiple quadrants of restorative dental treatment. A retrospective chart review was conducted looking at Frankl score of children with and without music. The child's behavior was observed and rated using Frankl scores with music and without music

\section{Inclusion Criteria}

- $\quad$ Patients 6 to 12 years old

- ASA I and II according to American Society of Anesthesiology

- $\quad$ Requires restorative dental procedure

- $\quad$ No nitrous oxide use during appointment

- Frankl score of 2 or 3 during prior restorative dental treatment

- At least two quadrants of restorative dental treatment needed.

\section{Exclusion Criteria}

- $\quad$ Patients under 6 and over 12 years of age

- $\quad$ ASA Class III or more according to American Society of Anesthesiology

- $\quad$ Patients with known behavioral diagnoses (eg . ADHD, bipolar disorder, or autism)

- Physically or mentally handicapped children

- $\quad$ Nitrous oxide used during appointment

The Frankl score with music and without music, and age was placed in the data collection sheet. Frankl score was compared to Frankl score of child without concomitant music.

\section{Analysis}

The paired t-test was used in this study for statistical analysis. Paired t test is used when there are multiple pairs of observations. It tests whether the mean is different. It will test behavior of children under going restorative dental treatment without music compared to the behavior of children undergoing restorative dental treatment with music therapy.

$t=\frac{\bar{X}_{D}-\mu_{0}}{s_{D} / \sqrt{n}}$

- Difference of all pairs: $t$

- Average $X D$

- Standard deviation: $s D$

- Constant $\mu 0$

- Degree of freedom used is n-1

\section{Data Collection sheet}

\begin{tabular}{|c|c|c|}
\hline Age & $\begin{array}{l}\text { Frankle Score without } \\
\text { Music }\end{array}$ & Frankle Score with Music \\
\hline 8 & 3 & 3 \\
\hline 8 & 3 & 4 \\
\hline 8 & 3 & 3 \\
\hline 7 & 3 & 4 \\
\hline 11 & 3 & 4 \\
\hline 6 & 3 & 4 \\
\hline 8 & 3 & 4 \\
\hline 6 & 3 & 4 \\
\hline 6 & 3 & 4 \\
\hline 10 & 3 & 4 \\
\hline 7 & 3 & 4 \\
\hline 8 & 3 & 4 \\
\hline 7 & 3 & 3 \\
\hline 7 & 3 & 4 \\
\hline 7 & 2 & 2 \\
\hline 10 & 3 & 4 \\
\hline 9 & 2 & 2 \\
\hline 6 & 2 & 3 \\
\hline 7 & 3 & 4 \\
\hline 6 & 2 & 3 \\
\hline 10 & 3 & 3 \\
\hline 7 & 2 & 3 \\
\hline 7 & 3 & 3 \\
\hline 9 & 2 & 4 \\
\hline 11 & 3 & 4 \\
\hline 7 & 3 & 4 \\
\hline 10 & 3 & 4 \\
\hline 8 & 3 & 4 \\
\hline 8 & 3 & 3 \\
\hline 8 & 3 & 4 \\
\hline 6 & 3 & 4 \\
\hline 8 & 3 & 3 \\
\hline
\end{tabular}




\begin{tabular}{|c|c|c|}
\hline 9 & 3 & 4 \\
\hline 9 & 3 & 4 \\
\hline 10 & 3 & 4 \\
\hline 10 & 2 & 4 \\
\hline 9 & 1 & 2 \\
\hline 6 & 3 & 4 \\
\hline 7 & 3 & 4 \\
\hline 10 & 3 & 3 \\
\hline 8 & 3 & 4 \\
\hline 8 & 3 & 4 \\
\hline 8 & 3 & 3 \\
\hline 6 & 2 & 4 \\
\hline 6 & 2 & 4 \\
\hline 10 & 3 & 4 \\
\hline 9 & 3 & 4 \\
\hline 10 & 2 & 4 \\
\hline 11 & 3 & 2 \\
\hline 9 & 2 & 3 \\
\hline 10 & 3 & \\
\hline & & 2 \\
\hline
\end{tabular}

\section{Results}

Figure 1-6.

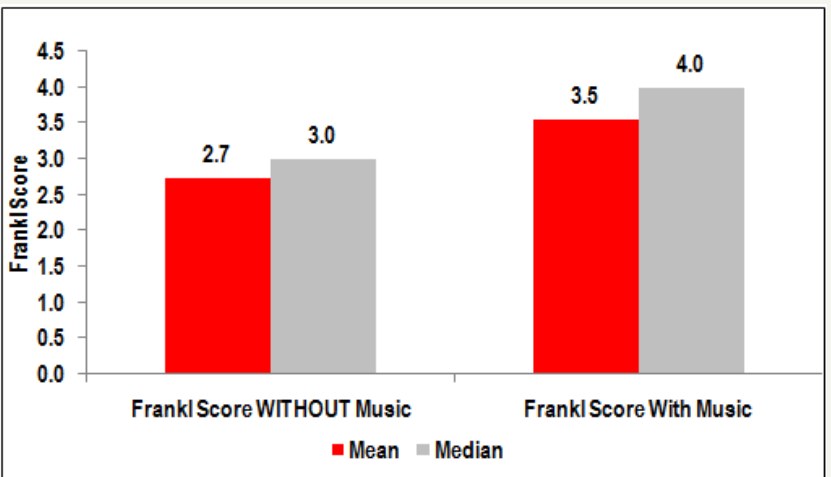

Figure 1: All Ages. Mean difference (all ages) from Frankl score with music and without music is .8 and the difference in the Mean 1.

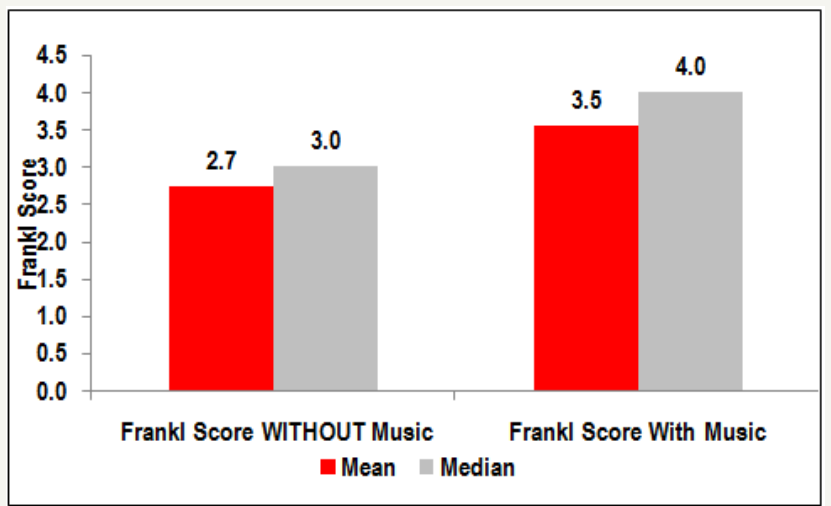

Figure 2: 6yr old. Mean difference (6yr old) from Frankl score with music and without music is .8 and the difference in the Mean 1.

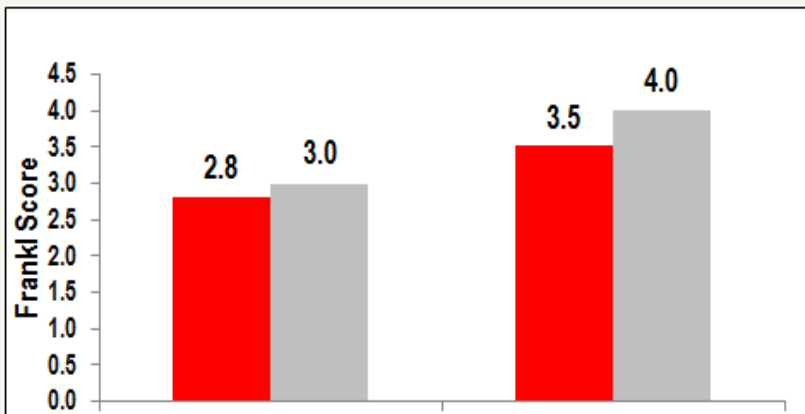

Frankl Score WITHOUT Music Frankl Score With Music

Figure 3: 7yrs old. Mean difference (7yr old) from Frankl score with music and without music is .7 and the difference in the Mean 1.

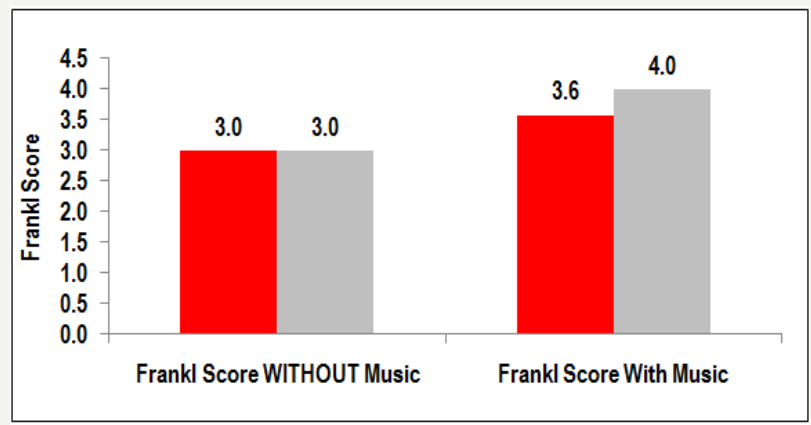

Figure 4: 8yrs old. Mean difference (8yr old) from Frankl score with music and without music is .6 and the difference in the Mean 1.

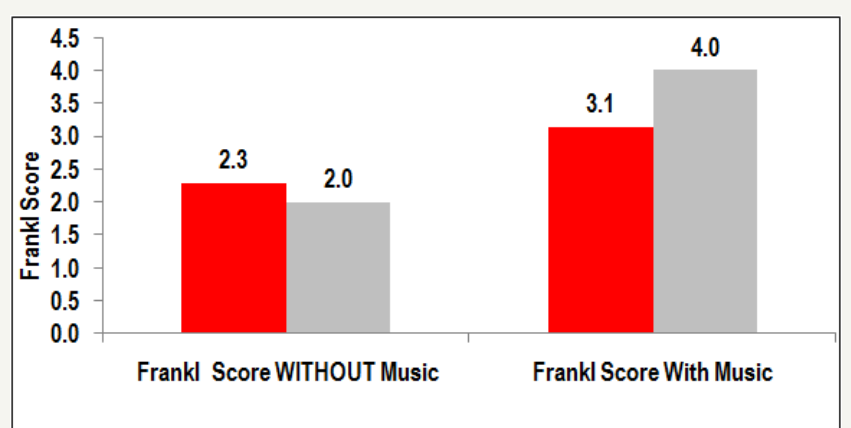

Figure 5: 9yrs old. Mean difference (9yr old) from Frankl score with music and without music is . 8 and the difference in the Mean 2

\section{Discussion}

The soothing power of music is well established. It is linked to emotions; it can be an extremely effective stress management tool. Listening to music has an relaxing effect on our minds and bodies. Music can have a favorable effect on our physiological functions, such as slowing the pulse and heart rate, lowering blood pressure, and decreasing stress hormones. Music can consume attention, and acts as a distraction. It can aid in meditation and help to prevent the mind digressing. 


\section{Interpretation of Paired T-Test Results}

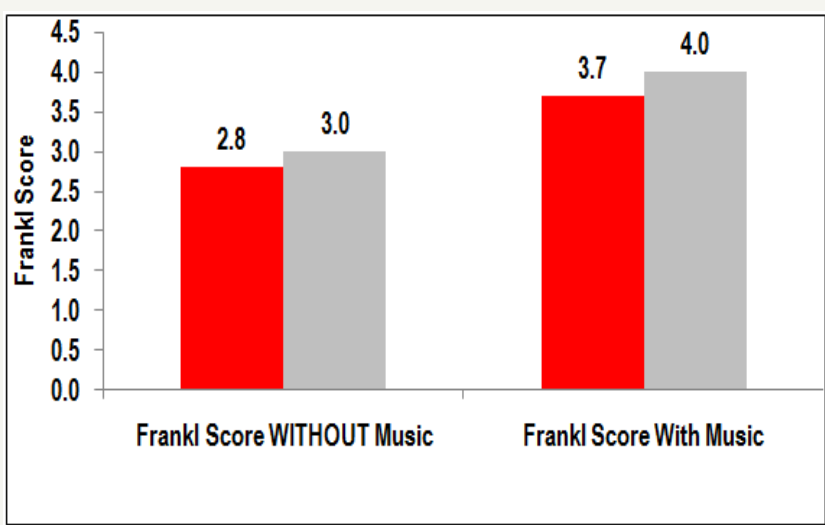

Figure 6: 10yrs old. Mean difference (10 yrs old) from Frankl score with music and without music is .9 and the difference in the Mean 1.

With a positive difference of 0.8039 in the Frankl score and a corresponding $\mathrm{p}$-value of $<0.0001$, it implies that patients who received music therapy had significantly higher Frankl Score compared to those who did not receive music therapy.

\section{Interpretation of Correlation Analysis}

When the correlation between age and difference in Frankl Score was examined, a correlation coefficient, $r=-0.173$ with a corresponding p-value of 0.2252 were obtained. Since the $p$-value of 0.2252 is greater than 0.05 , it implies that the age of the patients was not correlated with difference in Frankl scores. A negative correlation coefficient, although not statistical significant implies that the music therapy favored the younger children.

\section{Limitation}

a) Unable to obtain previous provider's behavioral techniques during dental treatment with local anesthesia. b) Limited number of participants.

c) Variations of Frankl score ratings from previous providers.

\section{Conclusion}

i. Patients with music therapy had an higher Frankl Score compared to children receiving dental treatment without music.

ii. There was no difference associated with age and Frankl score.

\section{References}

1. Bezabih S, Fantaye W, Tesfaye M (2013) Dental anxiety: prevalence and associated factors, among children who visited Jimma University Specialized Hospital Dental Clinic. Ethiop Med J 51(2): 115-121.

2. Marwah N, Prabhakar AR, Raju OS (2005) Music distraction-Its efficacy in management of anxious pediatric dental patients. J Indian Soc Pedod Prev Dent 23(4): 168-170.

3. Lahmann C, Schoen R, Henningsen P, Ronel J, Muehlbacher M, et a.l (2008) Brief relaxation versus music distraction in the treatment of dental anxiety. J Am Dent Assoc 139(3): 317-324.

4. Chlan L (1998) Effectiveness of a music therapy intervention on relaxation and anxiety for patients receiving ventilatory assistance. Heart Lung 27(3): 169-176.

5. Kain ZN, Caldwell-Andrews AA, Krivutza DM, Weinberg ME, Gaal D, et al. (2004) Interactive music therapy as a treatment for preoperative anxiety in children: a randomized controlled trial. Anesth Analg 98(5): 1260-1266.

6. Colt HG, Powers A, Shanks TG (1999) Effect of music on state anxiety scores in patients undergoing fiber optic bronchoscopy. Chest 116(3): 819-824.

7. Kettwich SC, Sibbitt WL, Brandt JR, Johnson CR, Wong CS, et al. (2007) Needle phobia and stress-reducing medical devices in pediatric and adult chemotherapy patients. J Pediatr Oncol Nurs 24(1): 20-28.

8. Dean JA, Avery DR, McDonald RE (2010) McDonald and Avery dentistry for the child and adolescent. Elsevier Health Sciences, Chicago, USA.

\section{Your subsequent submission with Crimson Publishers} will attain the below benefits

- High-level peer review and editorial services

- Freely accessible online immediately upon publication

- Authors retain the copyright to their work

- Licensing it under a Creative Commons license

- Visibility through different online platforms

- Global attainment for your research

- Article availability in different formats (Pdf, E-pub, Full Text)

- Endless customer service

- Reasonable Membership services

- Reprints availability upon request

- One step article tracking system 